\title{
Galvanic influence on pyrite and chalcopyrite oxidation rates under floatation $\mathrm{pH}$ condition
}

\author{
SANA ISHIDA ${ }^{1}$, JIFENG XUE ${ }^{1}$, SHIGESHI FUCHIDA ${ }^{2}$, \\ YUJI AOKI ${ }^{3}$, TAKUYA KASEYAMA ${ }^{3}$, YOSHINOBU \\ KISHIMOTO $^{3}$ AND CHIHARU TOKORO ${ }^{2}$ \\ ${ }^{1}$ Graduate School of Creative Science and Engineering, Waseda \\ University \\ ${ }^{2}$ Waseda University \\ ${ }^{3}$ Sumitomo Metal Mining, Company Limited \\ Presenting Author: ksnzng28@asagi.waseda.jp
}

Pyrite is the most common mineral in copper ore, and selective separation of valuable copper minerals in the floatation is an important process because of no economic value of pyrite. Floatability of pyrite and copper mineral could relate to the oxidation state of their surfaces, because non-oxidized surface and secondary minerals control in reactivity to floatation regents. In this study, we evaluated initial oxidation rate of pyrite and chalcopyrite at $\mathrm{pH} 9$ and 12 and their interactions in the mix reaction system (chalcopyrite/pyrite ratio $(\mathrm{cp} / \mathrm{py})=0,0.03,0.3$, and 1) to estimate an optimal chemical condition for the floatation.Our previous experiment have revealed pyrite oxidation rate become 2-order of magnitude higher than that of chalcopyrite under the floatation $\mathrm{pH}$ condition, assuming that the pyrite oxidation can be the dominant reaction in the mixed system. Compared with single pyrite experiment, pyrite oxidation rate would become less about 1-orders of magnitude at the high cp/py condition $(>0.3)$ at $\mathrm{pH} 12$, where oxidation is most advanced. This result shows the galvanic protection of pyrite oxidation by interaction with chalcopyrite, which has a low resting potential ${ }^{1)}$. The mix reaction was found to be a twostep reaction similar to the single component system. It can be seen that the effect of the py/cp ratio is greatly affected in the late reaction period. In addition, the mix oxidation rate reduced by only $10^{-9}\left(\mathrm{~mol} / \mathrm{m}^{2} / \mathrm{s}\right)$ under high $\mathrm{cp} / \mathrm{py}$ conditions $(>0.3)$ at $\mathrm{pH} 9$ compared to a single pyrite system. At higher $\mathrm{pH}$ condition, the faster the reaction rate between dissolved oxygen and $\mathrm{Fe}^{2+}$, and the faster the production rate of $\mathrm{Fe}^{3+}$, which is the oxidizing agent. ${ }^{1)}$ The results of the mineral liberation analyzer of copper ore from South America shows pyrite was far superior to chalcopyrite $(\mathrm{cp} / \mathrm{py}<0.1)$, indicating the galvanic effect can be negligible under the floatation condition. The oxidation rate of each mineral is presumed to be similar to that of the single component system, and the floating property of each mineral is considered to depend on the oxidation rate of the surface.

1) Li, Y., Advances in Colloid and Interface Science(2013), 197-198. 